\title{
Genomic profile of Toll-like receptor pathways in traumatically brain-injured mice: effect of exogenous progesterone
}

\author{
Fang Hual', Jun Wang ${ }^{1}$, Tauheed Ishrat ${ }^{1}$, Wenjing Wei $^{2}$, Fahim Atif ${ }^{1}$, Iqbal Sayeed ${ }^{1}$ and Donald G Stein ${ }^{1}$
}

\begin{abstract}
Background: Traumatic brain injury (TBI) causes acute inflammatory responses that result in an enduring cascade of secondary neuronal loss and behavioral impairments. It has been reported that progesterone (PROG) can inhibit the increase of some inflammatory cytokines and inflammation-related factors induced by TBI. Toll-like receptors (TLRs) play a critical role in the induction and regulation of immune/inflammatory responses. Therefore, in the present study, we examined the genomic profiles of TLR-mediated pathways in traumatically injured brain and PROG's effects on these genes.

Methods: Bilateral cortical impact injury to the medial frontal cortex was induced in C57BL/6J mice. PROG was injected (i.p., $16 \mathrm{mg} / \mathrm{kg}$ body weight) at 1 and $6 \mathrm{~h}$ after surgery. Twenty-four hours post-surgery, mice were killed and peri-contusional brain tissue was harvested for genomic detection and protein measurement. RT-PCR arrays were used to measure the mRNA of 84 genes in TLR-mediated pathways. Western blot, ELISA and immunohistochemistry were used to confirm the protein expression of genes of interest.

Results: We found that 2 TLRs (TLR1 and 2), 5 adaptor/interacting proteins (CD14, MD-1, HSPA1a, PGRP and Ticam2) and 13 target genes (Ccl2, Csf3, IL1a, IL1b, IL1r1, IL6, IL-10, TNFa, Tnfrsf1a, Cebpb, Clec4e, Ptgs2 and Cxcl10) were significantly up-regulated after injury. Administration of PROG significantly down-regulated three of the 13 increased target genes after TBI (CCl-2, IL-1b and Cxcl-10), but did not inhibit the expression of any of the detected TLRs and adaptor/interacting proteins. Rather, PROG up-regulated the expression of one TLR (TLR9), 5 adaptor/ interacting proteins, 5 effectors and 10 downstream target genes. We confirmed that CCl-2, Cxcl-10, TLR2 and TLR9 proteins were expressed in brain tissue, a finding consistent with our observations of mRNA expression.

Conclusion: The results demonstrate that TBI can increase gene expression in TLR-mediated pathways. PROG does not down-regulate the increased TLRs or their adaptor proteins in traumatically injured brain. Reduction of the observed inflammatory cytokines by PROG does not appear to be the result of inhibiting TLRs or their adaptors in the acute stage of TBI.
\end{abstract}

Keywords: Toll-like receptors progesterone, traumatic brain injury, inflammation, mouse

\section{Background}

Traumatic brain injury (TBI) comprises a cascade of events that begins with a primary neuronal/glial insult and progresses to further proximal and distal cell loss. At the cellular level, the major effectors in this cascade are the activation of inflammatory responses including

\footnotetext{
* Correspondence: fhua2@emory.edu

'Department of Emergency Medicine, Brain Research Laboratory, Emory University School of Medicine, 1365B Clifton Rd, Atlanta, GA 30322, USA Full list of author information is available at the end of the article
}

the release of cytokines, chemokines and adhesion molecules, and the recruitment of leukocytes [1-6].

The neuroprotective action of progesterone (PROG) in TBI has been extensively studied by our laboratory and many others [7-11]. Given after a TBI, PROG has been shown to attenuate cerebral edema, improve spatial learning performance, reduce sensory neglect, and inhibit the increase of some inflammatory cytokines and inflammation-related factors, such as IL- $1 \beta$, TNF- $\alpha$, CFC3, GFAP and NFкB [7-14]. How the various immunological

\section{() Biomed Central}


and inflammatory responses in traumatically injured brain are activated and regulated, and the mechanisms underlying the neuroprotective effect of PROG against TBI, have not been fully elucidated.

The important regulators that mediate much of the inflammatory cascade are the Toll-like receptors (TLRs), a trans-membrane receptor family that has emerged as a key factor in the triggering of antimicrobial host defense responses by the innate immune system (Figure 1). At present, at least 10 human and 12 mouse TLRs have been reported to be expressed in a variety of mammalian immune-related cell types as well as non-immune cells including microglia, astrocytes, oligodendrocytes and neurons [15-21]. Each TLR recognizes its distinct ligands derived from various microorganisms initiating immunological and inflammatory responses [22,23]. For instance, TLR2 recognizes peptidoglycans (PGN), TLR4 recognizes lipopolysaccharide (LPS), and TLR9 recognizes viral CpG DNA [23]. Stressed and damaged cells can also release endogenous ligands which activate TLR-mediated signaling. Thus, immune inflammatory responses can be activated by an injury without the presence of invading pathogens [24]. Upon activation by exogenous and endogenous ligands, TLRs recruit a set of adaptors, including MyD88, TIRAP, TRIF and TRAM, and then activate downstream kinases and cellular signaling pathways which regulate the expression of genes triggering inflammation and immunity $[23,25,26]$.

Involvement of TLR-mediated signaling has been reported in central nervous system (CNS) diseases such as multiple sclerosis [27], Alzheimer's disease, Parkinson's disease, amyotrophic lateral sclerosis [28] and ischemic brain damage [25,29-32]. Recently, increased mRNAs for TLR1, 2, 4, 5, 7 and molecules associated with TLR signaling was reported in spinal cord after injury [33]. However, less is known about the genomic profile of the TLR-mediated pathways in the traumatically injured brain. Such knowledge could contribute to

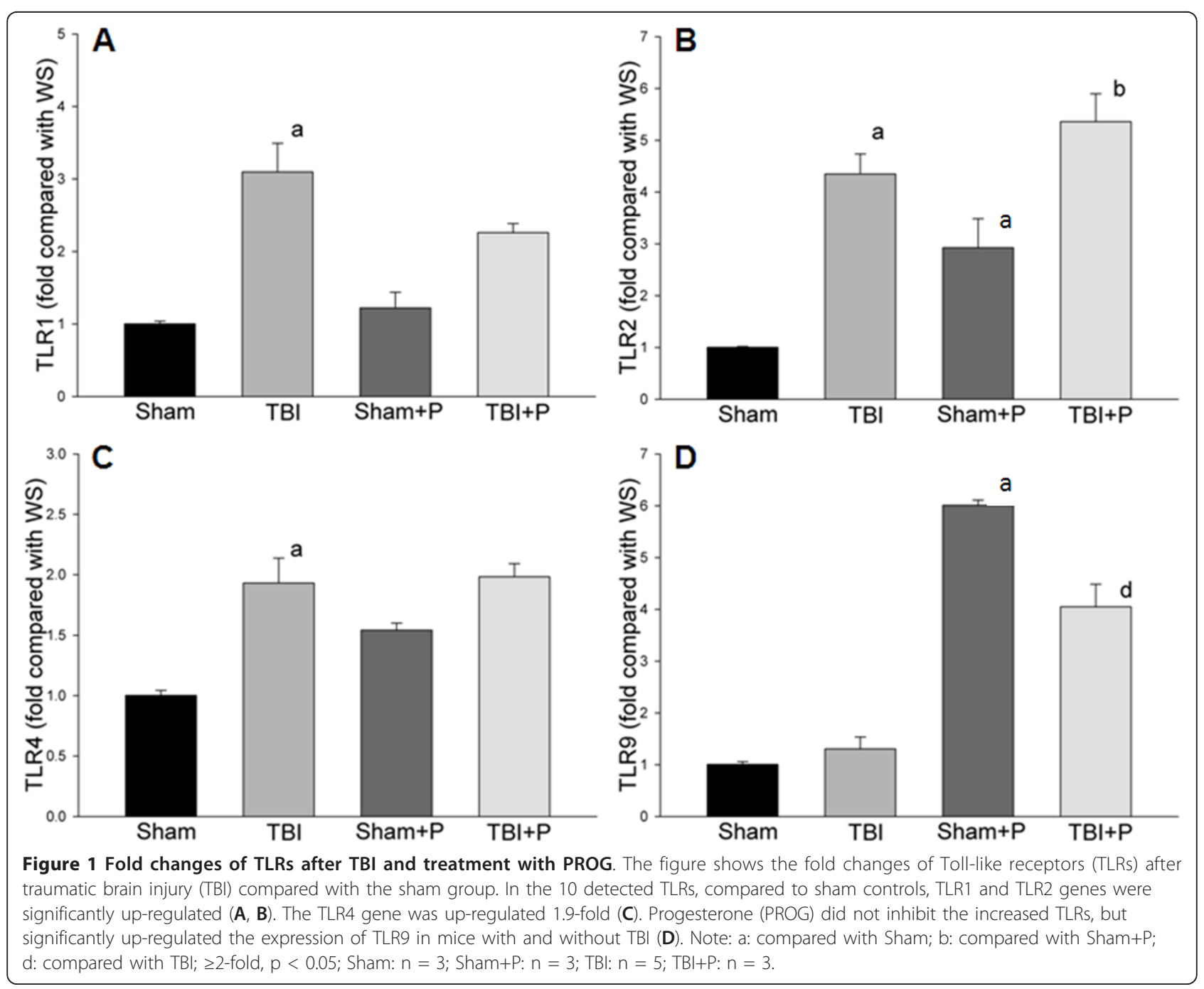


a better understanding of the pathology of secondary damage after brain injury and to the mechanisms of action of PROG in enhancing neuroprotection after injury. In the present study, $\mathrm{RT}^{2}$ Profiler PCR arrays were used to detect the mRNA of 84 genes implicated in regulating TLR pathways in mice with TBI. We then examined the effect of PROG on the expression of these genes. The protein expression of TLR2, TLR9, Ccl-2 and Cxcl-10 was also investigated.

\section{Methods}

Animals

Male C57BL/6J mice with body weights between 25 and $30 \mathrm{~g}$ were obtained from the Jackson Laboratory and maintained in the Division of Laboratory Animal Resources at Emory University. The experiments outlined in this manuscript conform to the Guide for the Care and Use of Laboratory Animals published by the National Institutes of Health (NIH Publication No. 85-23, revised 1996). Animal care and experimental protocols (150-2009) were approved by the Emory University Committee on Animal Care. Mice were assigned to one of four groups: sham-injury control plus vehicle (Sham, $\mathrm{n}=11)$, TBI plus vehicle (TBI, $\mathrm{n}=15)$, shaminjury plus PROG treatment $($ Sham $+\mathrm{P}, \mathrm{n}=11)$, and TBI plus PROG treatment $(\mathrm{TBI}+\mathrm{P}, \mathrm{n}=13)$. PROG was purchased from Sigma-Aldrich Co. (St. Louis, MO; Cat No. 7556). Based on the previous dose-response studies of PROG in animals [14,34], we used a dose of $16 \mathrm{mg} / \mathrm{kg}$ body weight. PROG was injected intraperitoneally (IP) in Sham $+\mathrm{P}$ and $\mathrm{TBI}+\mathrm{P}$ groups at 1 and $6 \mathrm{~h}$ after surgery. The sham and TBI-only groups were injected with the same volume of vehicle.

\section{Induction of TBI}

Bilateral cortical impact injury (CCI) to the medial frontal cortex (MFC) has been previously described [35], and was modified for mice in this experiment as follows: mice were weighed and anesthesia was induced by $5.0 \%$ isoflurane (Webster Veterinary Supply, Inc., Sterling, MA). The scalp was shaved using electric hair clippers and the exposed skin disinfected with iodine tincture. The trachea was intubated with a 20-gauge intravenous catheter. Anesthesia was maintained by inhalation of $1.5 \%$ to $2 \%$ isoflurane driven by oxygen flow by a Laboratory Animal Anesthesia System (VetEquip, Pleasanton, CA). The lungs were mechanically ventilated at a rate of 110 breaths per min with a delivered tidal volume of $0.5 \mathrm{ml}$. The mice were mounted in a stereotaxic device with their heads in a horizontal position. Body core temperature was maintained at $37^{\circ} \mathrm{C}$ with a homeothermic heating blanket system (TC-1000; CWE Inc., Ardmore, PA). Blood $\mathrm{SpO}_{2}$ was monitored and maintained at levels $\geq 90 \%$ using a SurgiVet ${ }^{\mathrm{TM}}$ pulse oximeter (model V3304; Waukesha, WI). Under aseptic conditions, the mice were secured in a prone position, and a midline sagittal scalp incision was made using sterile technique. A contusion was produced on the exposed cortex (the anterior-posterior coordinate for the epicenter of the injury was bregma $-1.0 \mathrm{~mm}$ ) using a magnetic impactor device. The impactor, containing a $2.0 \mathrm{~mm}$ diameter rod tip, compressed the cortex at $3.5 \mathrm{~m} / \mathrm{s}$ to a depth of $1 \mathrm{~mm}$ with a dwell time of $100 \mathrm{~ms}$. The incision was sutured and the mice were allowed to achieve spontaneous respiratory effort prior to extubation. Sham control animals underwent surgical procedures identical to those for the TBI group, but no impact was delivered. After awakening, the mice were placed in a holding cage at $31^{\circ} \mathrm{C}$ for 2 hours and then returned to their housing in the animal care room.

\section{Preparation of tissue for extraction of RNA}

Since most inflammatory factors increase within $24 \mathrm{~h}$ after initial insult to brain and PROG is known to inhibit many of these inflammatory factors in the early stage of TBI, the time point of $24 \mathrm{~h}$ after injury was selected for tissue analysis. Thus, $24 \mathrm{~h}$ after TBI and sham operations, 3 mice from the sham group, 5 mice from the TBI group, 3 mice from the Sham $+\mathrm{P}$ group and 3 mice from the TBI $+\mathrm{P}$ group were killed and peri-contusional brain tissue (brain area within $3 \mathrm{~mm}$ of the epicenter of the injury) was harvested using a biopsy puncture (6 $\mathrm{mm}$ diameter), snap-frozen in liquid nitrogen and stored at $-80^{\circ} \mathrm{C}$ for PCR array. To confirm the expressed genes are from brain or blood-derived cells, 3 mice in each group were euthanized, perfused with ice-cold PBS via the ascending aorta, and then peri-contusional brain tissue (brain area within $3 \mathrm{~mm}$ of the epicenter of the injury) was harvested.

\section{Extraction of RNA}

RNA was extracted from the tissue using the TRIzol ${ }^{\circledR}$ protocol (15596-026; Invitrogen, Carlsbad, CA). For PCR array, after ethanol precipitation, the RNA was further cleaned using SABiosciences's RT2 qPCR-Grade RNA Isolation Kit (PA-001; Frederick, MD) according to the manufacturer's protocol. RNA quality was analyzed and met the required criteria for RT-PCR arrays and RT-PCR TaqMan ${ }^{\circledR}$ Gene Expression Assays.

\section{Real-time PCR arrays}

RT-PCR arrays were performed by SABiosciences. cDNAs were synthesized using an $\mathrm{RT}^{2}$ First Stand Kit (SABiosciences) according to its protocol. The reaction was performed at $42^{\circ} \mathrm{C}$ for $15 \mathrm{~min}$ and then stopped immediately by heating at $95^{\circ} \mathrm{C}$ for $5 \mathrm{~min}$. Mouse TLR signaling pathway PCR array kits were purchased from SABiosciences (PAMM-018). This kit profiles the 
expression of 84 genes related to TLR-mediated signal transduction and 5 housekeeping genes (GUSB, HPRT1, HSP90ab1, GADPH and ACTB). Genes are functionally grouped as TLR, adaptor and interacting proteins, effectors, downstream pathways and target genes, including $\mathrm{NF} \kappa \mathrm{B}$ pathway, JNK/p38 pathway, NF/IL6 pathway, IRF pathway, and the regulation of adaptive immunity group (Table 1). A negative control for genomic DNA and contaminating RNA was also conducted in each sample.
Amplification, data acquisition, and the melting curve were carried out by the ABI 7900 Real Time PCR system (Applied Biosystems, Foster City, CA). The PCR cycling program was set as follows: stage $1: 95^{\circ} \mathrm{C}$ for $10 \mathrm{~min}$, stage $2: 95^{\circ} \mathrm{C}$ for $15 \mathrm{sec}$ followed by $60^{\circ} \mathrm{C}$ for 1 minute repeated for 40 cycles, and stage $3: 95^{\circ} \mathrm{C}$ for 15 sec, $60^{\circ} \mathrm{C}$ for $15 \mathrm{sec}$ and $95^{\circ} \mathrm{C}$ for $15 \mathrm{sec}$. The cycle threshold $(\mathrm{Ct})$ and melting curve of each gene were automatically established and recorded by the software.

Table 1 The detected genes of interest (GOI)

\begin{tabular}{|c|c|c|c|c|}
\hline \multirow[b]{2}{*}{ Genes } & \multirow[b]{2}{*}{ RefSeq } & \multicolumn{3}{|c|}{ Fold Changes } \\
\hline & & TBI/Sham & Sham+P/Sham & $\mathrm{TBI}+\mathrm{P} / \mathrm{TB}$ \\
\hline \multicolumn{5}{|c|}{ Toll-like receptors } \\
\hline TLR1 & NM_030682 & $2.99^{*}$ & 1.18 & -1.33 \\
\hline TLR2 & NM_011905 & $4.28^{*}$ & $2.82^{*}$ & 1.24 \\
\hline TLR3 & NM_126166 & 1.20 & 1.82 & 1.20 \\
\hline TLR4 & NM_021297 & $1.89^{*}$ & 1.54 & 1.05 \\
\hline TLR5 & NM_016928 & -1.28 & 1.49 & 1.47 \\
\hline TLR6 & NM_011604 & -1.12 & 1.88 & 1.70 \\
\hline TLR7 & NM_133211 & 1.52 & 2.04 & 1.78 \\
\hline TLR8 & NM_133212 & 1.79 & 3.44 & 1.55 \\
\hline TLR9 & NM_031178 & 1.21 & $6.01^{*}$ & $3.31^{*}$ \\
\hline Muc13 & NM_010739 & 1.15 & -1.76 & -1.39 \\
\hline \multicolumn{5}{|c|}{ Adaptors \& interacting proteins } \\
\hline Btk & NM_013482 & 1.56 & 1.81 & 1.24 \\
\hline Cd14 & NM_009841 & $7.51^{*}$ & 1.00 & -1.84 \\
\hline Hmgb1 & NM_010439 & -1.07 & 1.19 & 1.12 \\
\hline Hras1 & NM_008284 & -1.78 & 1.88 & $2.74^{*}$ \\
\hline Hspa1a & NM_010479 & $1.97^{*}$ & 1.3 & -1.37 \\
\hline Hspd1 & NM_010477 & 1.05 & -1.11 & -1.21 \\
\hline MD-1 & NM_010745 & $2.51^{*}$ & 1.06 & 1.02 \\
\hline Ly96 & NM_016923 & 1.08 & 1.01 & -1.07 \\
\hline Mapk8ip3 & NM_013931 & -1.09 & -1.04 & -1.06 \\
\hline MyD88 & NM_010851 & 1.33 & $2.86^{*}$ & $2.65^{*}$ \\
\hline Peli1 & NM_023324 & -1.16 & 1.77 & 1.82 \\
\hline Pglyrp1 & NM_009402 & $2.35^{*}$ & 1.64 & 1.34 \\
\hline Ripk2 & NM_138952 & 1.10 & 1.18 & 1.04 \\
\hline Ticam1 & NM_174989 & -1.99 & $8.98^{*}$ & $16.18^{*}$ \\
\hline Ticam2 & NM_173394 & $2.04^{*}$ & $4.87^{*}$ & $3.76^{*}$ \\
\hline Tirap & NM_054096 & 1.24 & 2.93 & $2.04^{*}$ \\
\hline Tollip & NM_023764 & -1.09 & 1.12 & 1.11 \\
\hline \multicolumn{5}{|l|}{ Effectors } \\
\hline Casp8 & NM_009812 & -1.03 & $2.10^{*}$ & $2.04^{*}$ \\
\hline Fadd & NM_010175 & 1.34 & $6.02^{*}$ & $4.63^{*}$ \\
\hline Irak1 & NM_008363 & -1.09 & 2.11 & 1.82 \\
\hline Irak2 & NM_172161 & -1.16 & $2.05^{*}$ & $2.58^{*}$ \\
\hline Map3k7 & NM_172688 & -1.31 & -1.01 & 1.08 \\
\hline $\mathrm{Nr} 2 \mathrm{C} 2$ & NM_011630 & -1.34 & 1.88 & $2.03^{*}$ \\
\hline Ppara & NM_011144 & -1.80 & $2.40^{*}$ & $2.72^{*}$ \\
\hline Eif2ak2 & NM_011163 & 1.80 & 1.16 & -1.37 \\
\hline Ube2n & NM_080560 & -1.15 & 1.02 & -1.01 \\
\hline Ube2v1 & NM_023230 & -1.11 & 1.44 & 1.45 \\
\hline
\end{tabular}


Table 1 The detected genes of interest (GOI) (Continued)

\begin{tabular}{|c|c|c|c|c|}
\hline \multicolumn{5}{|c|}{ Downstream and target genes } \\
\hline \multicolumn{5}{|c|}{$N F \kappa B$ pathway } \\
\hline $\mathrm{Ccl} 2$ & NM_011333 & $41.89^{*}$ & 1.15 & $-2.73^{*}$ \\
\hline Chuk & NM_007700 & 1.01 & 2.21 & 1.80 \\
\hline Csf2 & NM_009969 & 1.50 & 1.67 & -1.28 \\
\hline Csf3 & NM_009971 & $3.07^{*}$ & $3.26^{*}$ & $2.32^{*}$ \\
\hline Hrb1 (agfg1) & NM_010472 & -1.18 & 1.58 & 1.52 \\
\hline IKKb & NM_010546 & -1.50 & $2.66^{*}$ & $3.10^{*}$ \\
\hline$\| 1 a$ & NM_010554 & $2.03^{*}$ & -1.23 & -1.29 \\
\hline$\| 1 b$ & NM_008361 & $8.69 *$ & -1.17 & $-3.43^{*}$ \\
\hline$\| 1 \mathrm{r} 1$ & NM_008362 & $2.16^{*}$ & 1.18 & -1.28 \\
\hline$\| 2$ & NM_008366 & -1.10 & 1.26 & -1.45 \\
\hline 116 & NM_031168 & $5.17^{*}$ & $-2.17^{*}$ & -2.33 \\
\hline$\| 10$ & NM_010548 & $2.06^{*}$ & 1.91 & 1.47 \\
\hline$\| 12 a$ & NM_008351 & 1.20 & 1.64 & 1.44 \\
\hline Map3k1 & NM_011945 & -1.28 & 2.70 & 1.78 \\
\hline Nfkb1 & NM_008689 & 1.03 & 1.26 & 1.09 \\
\hline Nfkb2 & NM_019408 & 1.14 & $3.86^{*}$ & $3.69^{*}$ \\
\hline Nfkbia & NM_010907 & 1.22 & 1.29 & 1.35 \\
\hline Nfkbib & NM_010908 & 1.15 & -1.22 & -1.18 \\
\hline Nfkbil1 & NM_010909 & -1.22 & $5.17^{*}$ & $4.83^{*}$ \\
\hline Nfrkb & NM_172766 & -1.20 & 1.65 & 1.47 \\
\hline Rel & NM_009044 & 1.11 & 1.12 & 1.03 \\
\hline Rela & NM_009045 & -1.02 & $2.61^{*}$ & $2.6^{*}$ \\
\hline Tnf & NM_013693 & $19.31^{*}$ & -1.05 & -1.31 \\
\hline Tnfaip3 & NM_009397 & 1.04 & $2.07^{*}$ & $2.38^{*}$ \\
\hline Tnfrsfla & NM_011609 & $2.91^{*}$ & $5.1^{*}$ & $3.31^{*}$ \\
\hline Tradd & NM_001033161 & 1.09 & -1.02 & -1.14 \\
\hline \multicolumn{5}{|c|}{ JNK/p38 pathway } \\
\hline Elk1 & NM_007922 & -1.25 & $2.43^{*}$ & $2.13^{*}$ \\
\hline Fos & NM_010234 & 1.67 & 1.99 & 1.34 \\
\hline Jun & NM_010591 & $1.9^{*}$ & 1.56 & 1.1 \\
\hline Map2k3 & NM_008928 & 1.40 & 1.28 & -1.07 \\
\hline Map2k4 & NM_009157 & -1.26 & -1.37 & -1.34 \\
\hline Map3k1 & NM_011945 & -1.28 & 2.74 & 1.78 \\
\hline Mapk8 & NM_016700 & -1.45 & 1.73 & 1.94 \\
\hline Mapk9 & NM_016961 & -1.31 & 1.15 & 1.28 \\
\hline \multicolumn{5}{|c|}{ NF/IL6 pathway } \\
\hline Cebpb & NM_009883 & $2.06^{*}$ & -1.19 & -1.69 \\
\hline Clec4e & NM_019948 & $6.72^{*}$ & -1.35 & -1.43 \\
\hline ॥6ra & NM_010559 & 1.13 & 1.38 & 1.14 \\
\hline Ptgs2 & NM_011198 & $2.33^{*}$ & $1.99^{*}$ & 1.5 \\
\hline \multicolumn{5}{|l|}{ IRF pathway } \\
\hline Cxcl10 & NM_021274 & $22.99^{*}$ & -1.03 & $-4.46^{*}$ \\
\hline |fnb1 & NM_010510 & 1.03 & -1.86 & -1.66 \\
\hline Ifng & NM_008337 & 1.30 & 1.01 & 1.19 \\
\hline Irf1 & NM_008390 & 1.62 & 1.80 & 1.18 \\
\hline Irf3 & NM_016849 & 0.99 & 3.12 & 1.90 \\
\hline Tbk1 & NM_019786 & -1.17 & 1.28 & 1.31 \\
\hline \multicolumn{5}{|c|}{ Adaptive Immunity } \\
\hline CD80 & NM_009855 & 1.26 & 1.15 & 1.27 \\
\hline CD86 & NM_019388 & 1.20 & -1.11 & 1.00 \\
\hline Traf6 & NM_009424 & 1.24 & $4.57^{*}$ & $3.19^{*}$ \\
\hline
\end{tabular}


The delta $\mathrm{Ct}\left(\Delta \mathrm{C}_{\mathrm{t}}\right)$ method was used for PCR array data analysis. The normalized $\Delta \mathrm{C}_{\mathrm{t}}$ ) for each gene of interest (GOI) was calculated by deducting the average $\mathrm{Ct}$ of the 5 housekeeping genes (HKG) from the Ct of each GOI. Then the double delta $\mathrm{Ct}(\Delta \Delta \mathrm{Ct})$ for each GOI was calculated by deducting the average $\Delta \mathrm{Ct}$ of GOI in the sham group from the $\Delta \mathrm{Ct}$ of each GOI. The fold-change of each GOI compared to the sham group was calculated as $2^{-\Delta \Delta C t}$.

\section{TaqMan ${ }^{\circledR}$ Gene Expression Assays}

RT-PCR TaqMan ${ }^{\circledR}$ Gene Expression Assays were performed using TaqMan real-time PCR primers and probes for mouse TLR2 (Assay ID: Mm00442346_m1; RefSeq: NM_011905.3), TLR9 (Assay ID: Mm00446193_m1; RefSeq: NM_031178.2), Ccl-2 (Assay ID: Mm00441242_ m1; RefSeq: NM_011333.3), Cxcl-10 (Assay ID: Mm00445235_m1; RefSeq: NM_021274.1), and Hprt1 (Assay ID: Mm00446968_m1; RefSeq: NM_013556.2) purchased from Applied Biosystems. The synthesis of cDNA was performed using iScript ${ }^{\mathrm{TM}}$ Reverse Transcription Supermix for RT-qPCR (Bio-Rad, \#170-8841) according to its protocol at $42^{\circ} \mathrm{C}$ for $15 \mathrm{~min}$ and then stopped immediately by heating at $95^{\circ} \mathrm{C}$ for $5 \mathrm{~min}$. Realtime PCR was performed on CFX96 ${ }^{\mathrm{TM}}$ real-time PCR system (Bio-Rad) in 96-well format and $25 \mu$ l reaction volume per well using iQ Supermix (Bio-Rad, \#1708862). Hprt1 control was used for normalization. Each sample was measured in triplicate in a single RT-PCR run. The cycling program was set as follows: stage $1: 95^{\circ}$ $\mathrm{C}$ for $10 \mathrm{~min}$, stage $2: 95^{\circ} \mathrm{C}$ for $15 \mathrm{sec}$ (for denaturation) followed by $60^{\circ} \mathrm{C}$ (transcription) for 1 minute repeated for 40 cycles, and stage 3: $95^{\circ} \mathrm{C}$ for $15 \mathrm{sec}, 60^{\circ} \mathrm{C}$ for $15 \mathrm{sec}$ and $95^{\circ} \mathrm{C}$ for $15 \mathrm{sec}$. The double delta $\mathrm{Ct}(\Delta \Delta \mathrm{Ct})$ for each GOI was calculated by deducting the average $\Delta \mathrm{Ct}$ of GOI in the sham group from the $\Delta \mathrm{Ct}$ of each GOI. The fold-change of each GOI compared to the sham group was calculated as $2^{-\Delta \Delta C t}$.

\section{Western blot}

Twenty-four hours after surgery, 16 mice (3 from the sham group, 5 from the TBI group, 3 from the Sham $+\mathrm{P}$ group and 5 from the TBI+P group) were euthanized, perfused with ice-cold PBS via the ascending aorta until the perfusion buffer was clear from the right atrium, and then peri-contusional brain tissue (brain area within $3 \mathrm{~mm}$ of the epicenter of the injury) was harvested. Western blot was performed as previously described [31]. Briefly, proteins were extracted, electrophoresed with SDS-polyacrylamide gel, and transferred onto Hybond ECL membranes (Amersham Pharmacia, Piscataway, NJ). The ECL membranes were incubated with primary antibody followed by incubation with peroxidase-conjugated secondary antibodies. Signals were detected with the ECL system (Amersham Pharmacia) and quantified by scanning densitometry and computerassisted image analysis. The primary antibodies used were anti-TLR2 (Santa Cruz Biotechnology, Inc.) and anti-TLR9 (Abcam, Cambridge, MA). The specification of the antibodies were confirmed in our previous study and the data provided by the manufacture.

\section{Enzyme-linked immunosorbent assay (ELISA)}

Concentration of $\mathrm{Ccl}-2$ and $\mathrm{Cxcl}-10$ were examined by ELISA using $\mathrm{Ccl}-2$ and $\mathrm{Cxcl}-10$ ELISA assay kits (eBioscience Inc., San Diego, CA). For each sample, 10 $\mu \mathrm{g}$ of extracted protein was used for detection. The procedure followed manufacturer instructions. The absorbance was read on a spectrophotometer with a wavelength of $450 \mathrm{~nm}$ and a reference wavelength of $650 \mathrm{~nm}$. The concentrations of Ccl-2 and Cxcl-10 were calculated according to the standard curve and presented as $\mathrm{pg} / \mu \mathrm{g}$ protein.

\section{Immunohistochemistry (IHC) staining}

Twenty-four hours after surgery, two mice from each group were euthanized and perfused with ice-cold PBS followed by $4 \%$ paraformaldehyde in PBS $(\mathrm{PH}=7.4)$ via the ascending aorta. Brains were removed, post-fixed in $4 \%$ paraformaldehyde for $24 \mathrm{~h}$, and then stored at $4^{\circ} \mathrm{C}$ in a solution of $30 \%$ sucrose-PBS for two days. The brains were embedded in OCT and coronal sections were cut $10 \mu \mathrm{m}$ thick. TLR2 and TLR9 were co-stained with specific markers for neurons (NeuN) and astrocytes (GFAP). Immunofluorescent labeling was done by incubating primary antibodies overnight at $4{ }^{\circ} \mathrm{C}$ in humidified chambers. The next day slides were rinsed 3 times with TBS and incubated with directly conjugated secondary antibodies for $1 \mathrm{~h}$ at room temperature. Slides were coverslipped using aqueous mounting medium with DAPI. The co-localization of TLR2 and TLR9 with specific markers for neurons and astrocytes on the slide was observed and analyzed under a confocal microscope (Zeiss LSM 510). The first antibodies used were rabbit anti-TLR2 (Abbiotec, San Diego, CA), rabbit anti-TLR9 (Abcam), rat anti-GFAP (Invitrogen) and mouse Fluor 488 conjugated anti-NeuN (Millipore, Billerica, MA). The secondary antibodies used were Texas red conjugated donkey antibody to rabbit IgG (Abcam) and Cy2 conjugated goat antibody to rat IgG (Gene Tex, Inc, Irvine, CA). The negative control slides went through the same process except being incubated with primary antibodies, which were replaced by antibody dilute solution.

\section{Statistical analysis}

For PCR array and TaqMan ${ }^{\circledR}$ Gene Expression Assays, the numbers of normalized $\Delta \mathrm{Ct}$ for each GOI were used 
for group comparison by one-way ANOVA with the All Pairwise Multiple Comparison Procedures (Bonferroni ttest). Genes that were up-regulated or down-regulated by at least two-fold with $p$-value less than or equal to 0.05 were considered significant. The results from western blotting and ELISA were presented as mean \pm SE. One-way ANOVA with All Pairwise Multiple Comparison Procedures (Bonferroni t-test) was used to compare differences in groups.

\section{Results}

Changes in genes in TLR-mediated pathways after TBI

Of the 10 detected TLRs, TLR1 and TLR2 genes were significantly up-regulated in the brain-injured group compared to sham controls $(\geq 2$-fold, $\mathrm{p}<0.05$, Table 1 , Figure 1). The TLR4 gene was up-regulated 1.9-fold ( $\mathrm{p}<$ $0.05)$. Five of the 17 detected adaptor and TLR-interacting proteins (CD14, Hspa1a, Pglyrp-1, MD-1, and Ticam2) were significantly up-regulated ( $\geq 2$-fold, $\mathrm{p}<0.05$, Figure 2 ). None of the detected effectors of TLR-signaling were upregulated more than 2 -fold compared to the sham-operated group. Thirteen of 40 detected target genes of TLR pathways (Ccl-2, Csf3, IL-10, IL-1a, IL-1b, IL1r1, IL-6, TNF, Tnfrs1a, Cebpb, Clec4e, Ptgs2 and Cxcl-10) were significantly up-regulated $(\geq 2$-fold, $\mathrm{p}<0.05)$. Of the 84 detected genes, none was significantly down-regulated more than 2-fold compared to shams (Figure 3).
Genes down-regulated by PROG in TBI

Administration of PROG significantly reduced the mRNA expression of 3 of the increased genes in brain tissue after TBI (Ccl-2, IL-1b and Cxcl-10; $\geq 2$-fold, p < 0.05, Table 1 and Figure 3). PROG did not significantly down-regulate the increased mRNA of TLRs, adaptor or TLR-interacting proteins, or downstream target genes (Table 1, Figure 1 and 2).

\section{Genes up-regulated by PROG in brain tissue}

Administration of PROG significantly up-regulated 1 TLR (TLR9), 5 adaptor and interacting proteins (Hras1, MyD88, Ticam1, Ticam2 and Tiap), 5 effectors (Casp8, Fadd, Irak2, Nr2c2 and Paea), and 10 downstream target genes (Csf3, Ikbkb, Lta, Nfkb2, Nfkbil1, Rela, Tnfaip3, Tnfrsf1a, Elk1 and Traf6) in TLR pathways compared to the untreated TBI group (Table 1).

\section{Changes in selected genes and their encoded proteins in TLR-mediated pathways in brain after TBI and PROG treatment}

The mRNA expression of selected genes, TLR2, TLR9, Cxcl-10 and Ccl-2, was confirmed using TaqMan ${ }^{\circledR}$ Gene Expression Assays in PBS-perfused brain tissue. The results showed that these genes increased and/or were modified by progesterone in brain tissue after TBI (Figure 4), which are consistent with the results from the

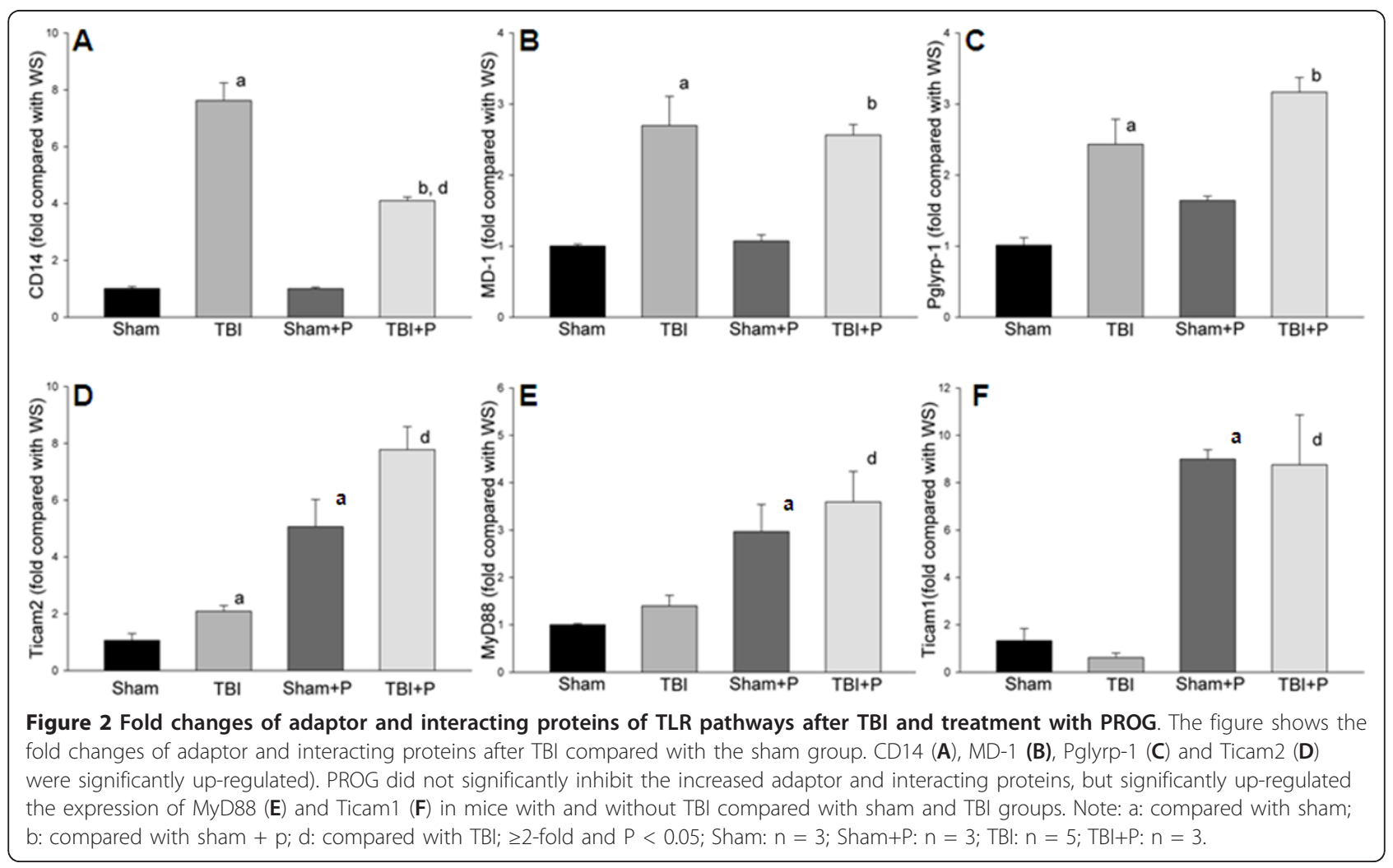




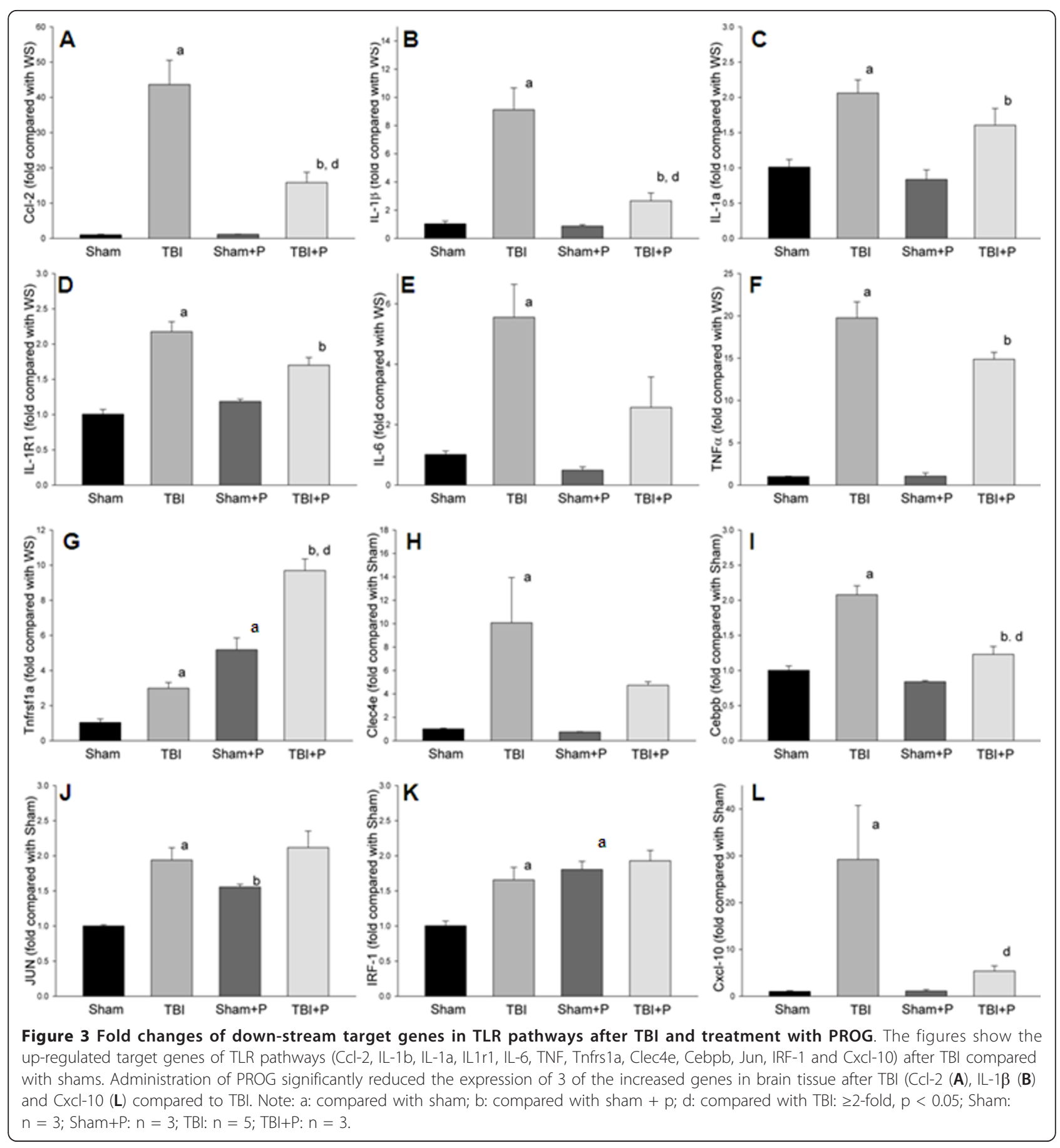

PCR-array. To confirm the changes in the proteins encoded by the genes in TLR-mediated pathways, we detected protein levels of TLR2 and TLR9, and the concentrations of $\mathrm{Ccl}-2$ and $\mathrm{Cxcl}-10$ using western blotting and ELISA in brain tissue from mice perfused with PBS. Western blots demonstrated that TBI induced an increase in TLR2, but not TLR9 $24 \mathrm{~h}$ after injury (Figure 5A, B). Treatment with PROG did not inhibit the increase of
TLR2. Rather, PROG increased the expression of TLR9 compared with untreated controls (Figure 5B). Results from ELISA showed that the concentrations of Ccl-2 and Cxcl-10 significantly increased in traumatically injured brain, and that administration of PROG inhibited the increase of Ccl-2 and Cxcl-10 24 hrs after TBI (Figure 5C, D). To determine the cellular location of TLR2 and TLR9 in traumatically injured brain, IHC co-staining was 


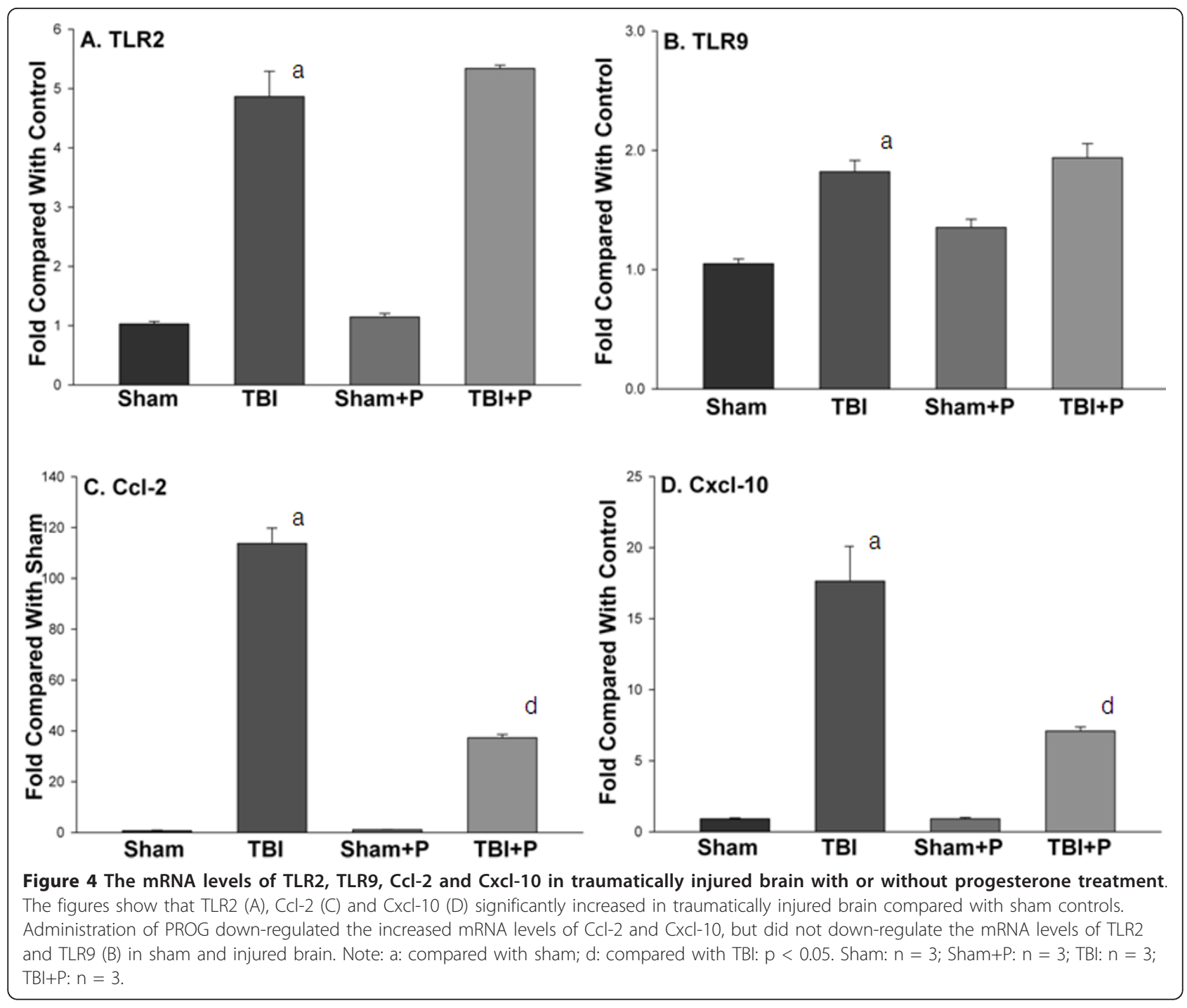

performed using specific anti-bodies for TLR2, TLR9, neuron mark (NeuN) and astrocyte marker (GFAP). TLR2 staining was evident in neurons in the cortex of injured brain (Figure 6A, B, C). However, very little colocalization of TLR2 with astrocytes was observed in the sections (Figure 6D, E, F). Weak expression of TLR9 colocalized with neurons was observed in cortex of the injured brain (Figure 6G, H, I). Colocalization of TLR9 with astrocytes was detected in the white matter of periventricular and subcortical regions of the brain (Figure 6J, K, L).

\section{Discussion}

TLR-mediated signaling pathways in brain injury

A substantial literature now shows that TLR-mediated signaling pathways play a critical role in the induction and regulation of innate immune/inflammatory responses which contribute to or amplify brain damage following an injury [31,32]. It appears that most inflammatory factors increase within $24 \mathrm{~h}$ after initial insult [1-6]. Given soon enough, PROG can inhibit many of these factors $[10,36]$. Because the injury cascade begins so quickly, we chose to examine TLRs and related genes soon after the initial trauma (24 h).

The present study demonstrated that two TLRs (TLR1 and TLR2) and five adaptor and interacting proteins (CD14, HSPA1a, Pglyrp-1, MD-1, and Ticam2) were significantly up-regulated by TBI (Table 1, Figure 1 and $2)$. Of the downstream target genes, 12 genes in the MyD88-dependent pathway (Ccl-2, Csf3, Il10, Il1a, Il1b, Il1r1, Il6, TNFa, Tnfrsf1a, Cebpb, Clec4e and Ptgs-2) and only one in the TRIF-IRF pathway (Cxcl-0) increased in brain tissue $24 \mathrm{~h}$ after TBI (Table 1 and Figure 3 ). The results from western blotting and ELISA confirmed that protein levels of TLR2, TLR9, Ccl-2 and Cxcl-10 increased in traumatically injured brain (Figure 5). Immunohistochemistry co-staining demonstrated that 


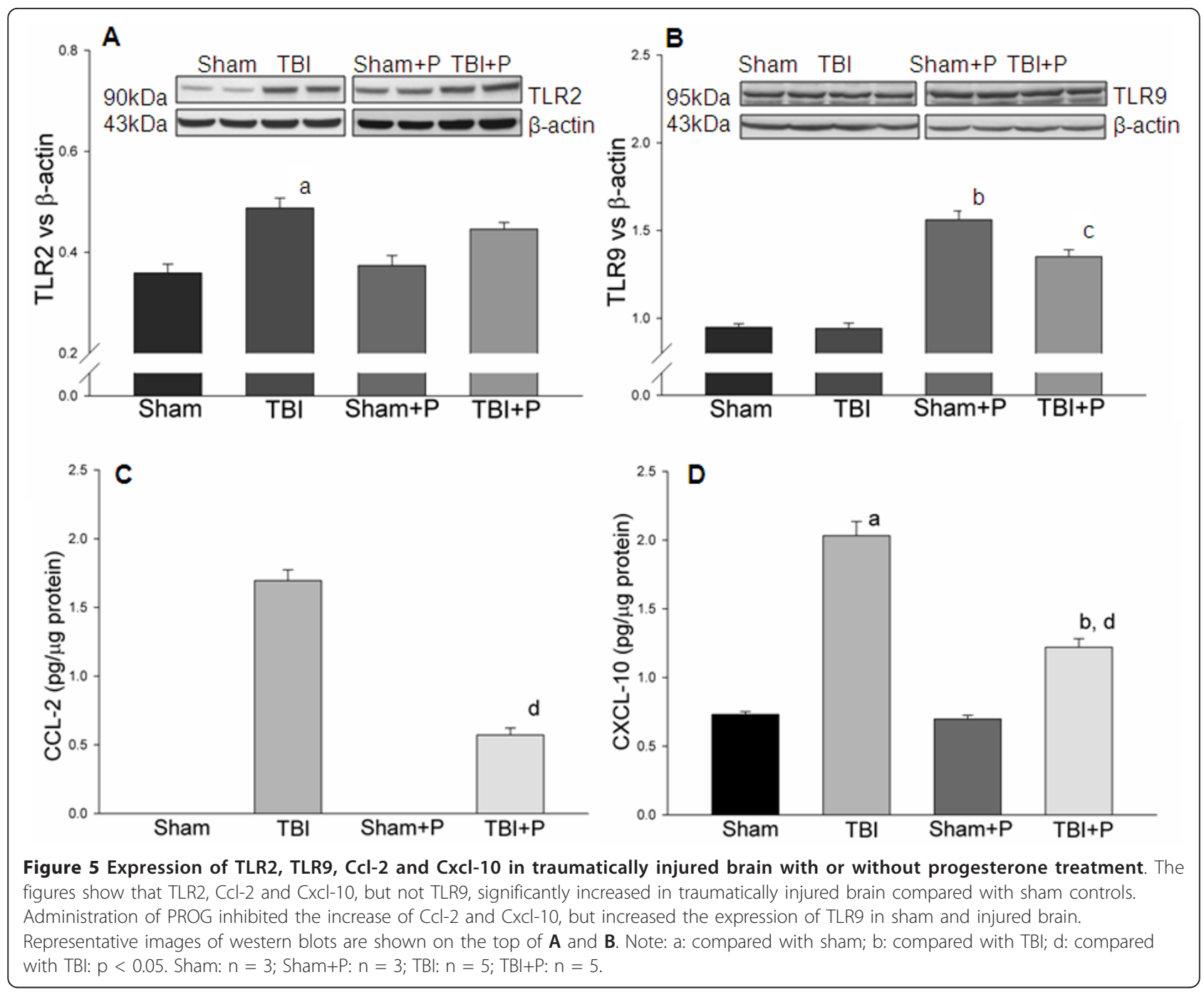

TLR2 was expressed mainly in neurons, and that TLR9 was expressed weakly in neurons, but stronger in astrocytes (Figure 6). A similar analysis in traumatically injured spinal cord performed by Kigerl and colleagues [33] showed that mRNA for TLR1, 2, 4, 5, 7, and molecules associated with TLR signaling TLR, such as CD14, MyD88, Traf6, Mal, Tollip, ІкB $\alpha$ and NFкB, significantly increased in injured spinal cord. Our results showing that TLR1, TLR2 and CD14 increased after TBI are consistent with Kigerl's report. However, the expression of several genes was different between spinal cord injury and TBI. For example, increased TLR5 TLR7, MyD88, Traf6, IкB $\alpha$ and NFKB were observed in spinal cord, but not in the traumatically injured brain. This variation can be explained by the different anatomic structures and cellular distribution between brain and spinal cord. In addition, the different injury models and time points should also be considered.
Since TLR1 forms heterodimers with TLR2 and then activates down-stream signaling through TLR2, we think that TLR2-mediated signaling is an important pathway in the pathology of TBI. In addition, HSPAla functions as a molecular chaperone and has been identified as an endogenous ligand of TLR2 or TLR4, which mobilizes NF-kB and induces cytokine synthesis through its interaction with TLR2 or TLR4 [37]. CD14 is an extracellular component of TLR4 which functions as a co-receptor required by the activation of TLR4 induced by lipopolysaccharide (LPS) [23]. MD-1, also known as Ly86, interacting with RP105, plays an important role in the TLR4 signaling pathway $[38,39]$. Ticam 2 physically bridges TLR 4 and TICAM-1 and functionally transmits LPS-TLR4 signaling to TICAM-1, which in turn activates IRF-3 [40]. The results show that the 5 adaptor and interacting proteins up-regulated by TBI are closely related to TLR2 and TLR4-mediated signaling. Moreover, the data showing 

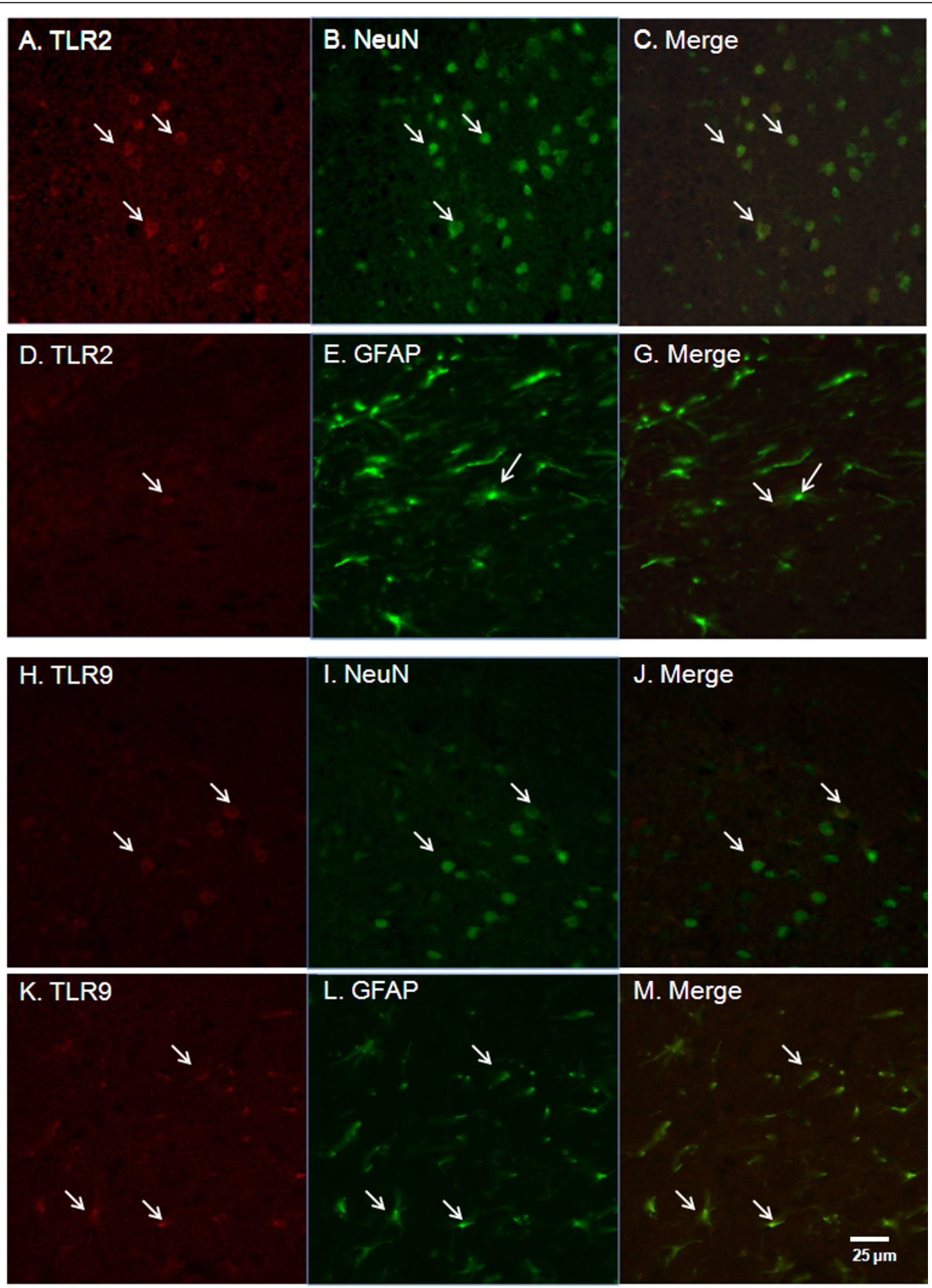

Figure 6 Immunohistochemical co-staining for TLR2 and TLR9 with NeuN and GFAP. IHC co-staining of TLR2 and TLR9 with specific markers for neurons (NeuN) and astrocytes (GFAP) was performed and observed under a confocal microscope. The first antibodies used were rabbit anti-TLR2, rabbit anti-TLR9, rat anti-GFAP and mouse Fluor 488 conjugated anti-NeuN. The secondary antibodies used were Texas red conjugated donkey antibody to rabbit lgG and Cy2 conjugated goat antibody to rat lgG. The images show that TLR2 staining co-localized with neurons in the cortex of injured brain (A, B, C). However, co-localization of TLR2 with astrocytes was hardly observed in the brain section (D, E, F). Weak expression of TLR9 was observed co-localized with neurons in cortex of the injured brain $(\mathbf{G}, \mathbf{H}, \mathbf{I})$. Co-localization of TLR9 with astrocytes was detected in the white matter of periventricular and subcortical regions of the brain $(\mathbf{J}, \mathbf{K}, \mathbf{L})$. 
that 12 down-stream target genes in the MyD88-dependent pathway and only one in the TRIF-IRF pathway (Cxcl10) increased in brain tissue, suggest that TBI most likely activates the MyD88-dependent pathway rather than the TRIF-dependent pathway.

We observed that the cytokines, Ccl-2, IL-1b, IL-6, TNF and Cxcl-10 increased more than 5-fold in the TBI group compared to sham controls. The inflammatory cytokines encoded by these five genes are well-known factors that can exacerbate secondary brain injury after TBI. We take our data to indicate that TBI is one of the stresses that up-regulates gene expression in TLR-mediated signaling pathways and that TLR2/TLR4mediated MyD88-dependent pathways are the most closely implicated in the unfolding pathophysiological processes following TBI.

\section{PROG affects TLR-mediated signaling pathways after brain injury}

Previous studies have indicated that PROG has multiple functions in the CNS, regulating cognition, mood, inflammation, mitochondrial function, neurogenesis and regeneration, myelination, and recovery from TBI (for recent reviews see $[9,10,41])$. Some PROG-regulated neural responses are mediated directly by PROG receptors (PR), which can be found in every neural cell type in the brain [41]. The PRs regulate gene expression, induce the transduction of signaling cascades, and activate transcription factors $[42,43]$.

Despite the large body of evidence suggesting that PROG protects brain from traumatic injury and improves functional outcomes, a full account of all the mechanisms underlying PROG's plieotropic and neuroprotective effects is far from completed. In the present study, administration of PROG significantly inhibited the up-regulation of some of the genes coding inflammatory cytokines in traumatically injured brain tissue. To our surprise, PROG did not down-regulate any of the detected TLRs, adaptor proteins, effectors, and other target genes in the TLR pathways. We take this finding to mean that PROG can down-regulate some, but not all, of the genes that encode inflammatory cytokine expression after TBI. This effect may be mediated through direct genomic regulation or through a variety of other non-genomic mechanisms [41-44]. Clearly, PROG did not affect the inflammatory response by inhibiting TLRs and their adaptor mRNA. PROG treatment did significantly increase gene expression of one TLR (TLR9), 5 adaptor/interacting proteins, 5 effectors and 10 downstream target genes (Table 1). Interestingly, most of the genes that were increased by PROG were not increased by TBI itself. The results from western blot and ELISA also confirmed that PROG increased the expression of TLR9 but not TLR2, and that PROG inhibited the increase of Ccl-2 and Cxcl-10 induced by TBI (Figure 5). Apparently PROG can regulate a number of TLR pathways by activating different functional gene groups that could have more indirect effects on the injury cascade and neural repair. It has been reported that activation of TLRs, such as TLR9, induced a neuroprotective effect on ischemic brain, which is possibly mediated by suppressing proinflammatory mediators and increasing neuroprotective factors [45]. Up-regulating genes in TLR-pathways may be one of a number of different mechanistic pathways by which PROG can protect the damaged brain from further tissue loss and subsequent functional deterioration. Given the fact that there are different pathways to neuroprotection, there is good reason to consider that combination therapies that would address the different signaling cascades initiated by CNS damage, would be a better approach than hoping to find a single agent that could 'do it all'.

In future research we will need to identify the cellular distribution and specific role of each functional gene regulated by PROG following TBI. It is also important to recognize that TBI and related disorders like stroke have substantial systemic effects that, depending on severity, are not limited to the brain $[46,47]$. There are now over 180 publications from around the world using more than 20 different injury models in 4 species, including humans, demonstrating the neuroprotective effects of PROG and its metabolites, so the effectiveness of the neurosteroid is clear despite the fact that all of its mechanisms of action are not yet known. Our findings demonstrate that PROG protects brain from injury via multiple mechanisms, such as including inhibition of neurotoxicity factors, mediating TLR-pathways and indirectly activating neuroprotective signaling.

\section{Conclusion}

Our study shows that TBI can increase gene expression in TLR-mediated pathways, and profiles some of this gene expression. Administration of PROG reduced the up-regulation of genes encoding inflammatory cytokines contributing to TBI, and mediated TLR signaling pathways.

List of Abbreviations Used

Cebpb: CCAAT/enhancer-binding protein beta; CD14: CD14 antigen; CCl-2: chemokine ( $\mathrm{C}-\mathrm{C}$ motif) ligand 2; $\mathrm{CxCl}-10$ : chemokine (C-X-C motif) ligand 10; Csf3: colony-stimulating factor 3; Clec4e: C-type lectin domain family 4 , member e; Prkr: eukaryotic translation initiation factor-2-alpha kinase-2; HSPA1a: heat shock protein 1A; IRF-3: interferon regulatory factor 3; II: Interleukin; IIr1: Interleukin 1 receptor 1; LPS: Lipopolysaccharide; MyD88: myeloid differentiation primary response gene 88; MD-1 or Ly86: myeloid differentiation 1; NFkB: nuclear transcription factor kappa B; PGN: peptidoglycans; Pglyrp-1: PGN recognition protein-1; Ptgs-2: Prostaglandinendoperoxide synthase 2; RIPK2: receptor-interacting serine-threonine kinase2; TRAF-6: TNF-receptor-associated factor-6; Tnfrsf1a: TNF receptor 
superfamily member 1A; TBI: traumatic brain injury; Ticam2: TIR domaincontaining adapter molecule 2; TRIF or Ticam-1: TIR-domain-containing adapter-inducing interferon- $\beta$; TLR: Toll-like receptor; TNFa: tumor necrosis factor $a$.

\section{Acknowledgements}

This work was supported by AHA National Program SDG $0830481 \mathrm{~N}$ to FH, Emory University URC Grant (2009-002) to FH, research funding from the Department of Pediatric Cardiovascular Surgery at the Children's Hospital of Atlanta and NIH 5R01NS048451 and 1R01HD061971 to DGS. This research was also supported in part by the Emory Biomarker Service Center and the Neuronal Imaging Core of the Emory Neuroscience NINDS core facilities grant (P30NS055077). A portion of this research was supported by a gift from BHR Pharma.

\section{Author details}

'Department of Emergency Medicine, Brain Research Laboratory, Emory University School of Medicine, 1365B Clifton Rd, Atlanta, GA 30322, USA. ${ }^{2}$ Department of Medicine, Emory University School of Medicine, Atlanta, GA 30322, USA

\section{Authors' contributions}

FH conceived and designed the study, performed surgery, collected data and wrote the manuscript. JW, TI, FA and IS performed the experiments and reviewed the manuscript. WW participated in the statistical analysis. DGS provided critical advice and worked on the manuscript. All authors read and approved the final manuscript.

\section{Competing interests}

DGS is entitled to royalty from products of BHR Pharma related to research on progesterone, and may receive research funding from BHR, which is developing products related to this research. In addition, the author serves as consultant to BHR and receives compensation for these services. The terms of this arrangement have been reviewed and approved by Emory University which receives the largest share of all licensing fees in accordance with its conflict of interest policies. Other authors declare that they have no conflicts of interest.

Received: 23 August 2010 Accepted: 8 May 2011 Published: 8 May 2011

\section{References}

1. Morganti-Kossmann MC, Satgunaseelan L, Bye N, Kossmann T: Modulation of immune response by head injury. Injury 2007, 38:1392-1400.

2. Harting MT, Jimenez F, Adams SD, Mercer DW, Cox CS Jr: Acute, regional inflammatory response after traumatic brain injury: Implications for cellular therapy. Surgery 2008, 144:803-813.

3. Homsi S, Federico F, Croci N, Palmier B, Plotkine M, Marchand-Leroux C, Jafarian-Tehrani M: Minocycline effects on cerebral edema: relations with inflammatory and oxidative stress markers following traumatic brain injury in mice. Brain Res 2009, 1291:122-132.

4. Israelsson C, Wang Y, Kylberg A, Pick CG, Hoffer BJ, Ebendal T: Closed head injury in a mouse model results in molecular changes indicating inflammatory responses. J Neurotrauma 2009, 26:1307-1314.

5. Cederberg D, Siesjö P: What has inflammation to do with traumatic brain injury? Childs Nerv Syst 2010, 26:221-226.

6. Ziebell JM, Morganti-Kossmann MC: Involvement of pro- and antiinflammatory cytokines and chemokines in the pathophysiology of traumatic brain injury. Neurotherapeutics 2010, 7:22-30.

7. Sayeed I, Stein DG: Progesterone as a neuroprotective factor in traumatic and ischemic brain injury. Prog Brain Res 2009, 175:219-237.

8. Stein DG: Progesterone exerts neuroprotective effects after brain injury. Brain Res Rev 2008, 57:386-397.

9. Stein DG, Sayeed I: Is progesterone worth consideration as a treatment for brain injury? AJR Am J Roentgenol 2010, 194:20-22.

10. Stein DG, Wright DW: Progesterone in the clinical treatment of acute traumatic brain injury. Expert Opin Investig Drugs 2010, 19:847-857.

11. Cekic M, Stein DG: Traumatic brain injury and aging: is a combination of progesterone and vitamin $\mathrm{D}$ hormone a simple solution to a complex problem? Neurotherapeutics 2010, 7:81-90.
12. Shear DA, Galani R, Hoffman SW, Stein DG: Progesterone protects against necrotic damage and behavioral abnormalities caused by traumatic brain injury. Exp Neurol 2002, 178:59-67.

13. He J, Evans CO, Hoffman SW, Oyesiku NM, Stein DG: Progesterone and allopregnanolone reduce inflammatory cytokines after traumatic brain injury. Exp Neurol 2004, 189:404-412.

14. Pettus EH, Wright DW, Stein DG, Hoffman SW: Progesterone treatment inhibits the inflammatory agents that accompany traumatic brain injury. Brain Res 2005, 1049:112-119.

15. Aderem A, Ulevitch RJ: Toll-like receptors in the induction of the innate immune response. Nature 2000, 406:782-787.

16. Akira S, Takeda K, Kaisho T: Toll-like receptors: critical proteins linking innate and acquired immunity. Nat Immunol 2001, 2:675-680.

17. Casanova JL, Abel L, Quintana-Murci L: Human TLRs and IL-1Rs in Host Defense: Natural Insights from Evolutionary, Epidemiological, and Clinical Genetics. Annu Rev Immunol 2011, 23:447-491.

18. O'Neill LA: How Toll-like receptors signal: what we know and what we don't know. Curr Opin Immunol 2006, 18:3-9.

19. Takeda K, Akira S: Toll-like receptors in innate immunity. Int Immunol 2005, 17:1-14.

20. Crack PJ, Bray PJ: Toll-like receptors in the brain and their potential roles in neuropathology. Immunol Cell Biol 2007, 85:476-480.

21. Mishra BB, Mishra PK, Teale JM: Expression and distribution of Toll-like receptors in the brain during murine neurocysticercosis. J Neuroimmunol 2006, 181:46-56.

22. Brightbill HD, Modlin RL: Toll-like receptors: molecular mechanisms of the mammalian immune response. Immunology 2000, 101:1-10.

23. Naert G, Laflamme N, Rivest S: Toll-like receptor 2-independent and MyD88-dependent gene expression in the mouse brain. J Innate Immun 2009, 1:480-493.

24. Shimada M, Yanai Y, Okazaki T, Noma N, Kawashima I, Mori T, Richards JS: Hyaluronan fragments generated by sperm-secreted hyaluronidase stimulate cytokine/chemokine production via the TLR2 and TLR4 pathway in cumulus cells of ovulated COCs, which may enhance fertilization. Development 2008, 135:2001-2011.

25. Marsh BJ, Williams-Karnesky RL, Stenzel-Poore MP: Toll-like receptor signaling in endogenous neuroprotection and stroke. Neuroscience 2009, 158:1007-1020.

26. Jenkins KA, Mansell A: TIR-containing adaptors in Toll-like receptor signalling. Cytokine 2010, 49:237-244.

27. Prat A, Antel J: Pathogenesis of multiple sclerosis. Curr Opin Neurol 2005, 18:225-230.

28. Letiembre M, Liu Y, Walter S, Hao W, Pfander T, Wrede A, SchulzSchaeffer W, Fassbender K: Screening of innate immune receptors in neurodegenerative diseases: A similar pattern. Neurobiol Aging 2007, 30:759-768.

29. Doyle KP, Simon RP, Stenzel-Poore MP: Mechanisms of ischemic brain damage. Neuropharmacology 2008, 55:310-318.

30. Gao Y, Fang $X$, Tong Y, Liu Y, Zhang B: TLR4-mediated MyD88-dependent signaling pathway is activated by cerebral ischemia-reperfusion in cortex in mice. Biomed Pharmacother 2009, 63:442-450.

31. Hua F, Ma J, Ha T, Kelley J, Kao RL, Schweitzer JB, Kalbfleisch JH, Williams DL, Li C: Differential Roles of TLR2 and TLR4 in acute focal cerebral ischemia/reperfusion injury in mice. Brain Research 2009, 1262:100-108.

32. Hua F, Ma J, Ha T, Xia Y, Kelley J, Williams DL, Kao RL, Browder IW, Schweitzer JB, Kalbfleisch JH, Li C: Activation of Toll-like receptor 4 signaling contributes to hippocampal neuronal death following global cerebral ischemia/reperfusion. J Neuroimmunol 2007, 190:101-111.

33. Kigerl KA, Lai W, Riverst S, Hart RP, Satoskar AR, Popovich PG: Progesterone Toll-like receptor (TLR)-2 and TLR-4 regulate inflammation, gliosis, and myelin sparing after spinal cord injury. J Neurochem 2007, 102:37-50.

34. Harburger LL, Saadi A, Frick KM: Dose-dependent effects of post-training estradiol plus progesterone treatment on object memory consolidation and hippocampal extracellular signal-regulated kinase activation in young ovariectomized mice. Neuroscience 2009, 160:6-12.

35. Wright DW, Hoffman SW, Virmani S, Stein DG: Effects of medroxyprogesterone acetate on cerebral oedema and spatial learning performance after traumatic brain injury in rats. Brain Inj 2008, 22:107-113. 
36. Pan DS, Liu WG, Yang XF, Cao F: Inhibitory effect of progesterone on inflammatory factors after experimental traumatic brain injury. Biomed Environ Sci 2007, 20:432-438.

37. Chase MA, Wheeler DS, Lierl KM, Hughes VS, Wong HR, Page K: Hsp72 induces inflammation and regulates cytokine production in airway epithelium through a TLR4- and NF-kappaB-dependent mechanism. J Immunol 2007, 179:6318-6324.

38. Kimoto M, Nagasawa K, Miyake K: Role of TLR4/MD-2 and RP105/MD-1 in innate recognition of lipopolysaccharide. Scand J Infect Dis 2003, 35:568-572.

39. Wang JY, Lin CG, Hsiao YH, Liou YH, Wu LS: Single nucleotide polymorphisms and haplotype of MD-1 gene associated with high serum IgE phenotype with mite-sensitive allergy in Taiwanese children. Int I Immunogenet 2007, 34:407-412.

40. Oshiumi H, Sasai M, Shida K, Fujita T, Matsumoto M, Seya T: TIR-containing adapter molecule (TICAM)-2, a bridging adapter recruiting to toll-like receptor 4 TICAM-1 that induces interferon-beta. J Biol Chem 2003, 278:49751-49762.

41. Brinton RD, Thompson RF, Foy MR, Baudry M, Wang J, Finch CE, Morgan TE, Pike CJ, Mack WJ, Stanczyk FZ, Nilsen J: Progesterone receptors: form and function in brain. Front Neuroendocrinol 2008, 29:313-339.

42. Allan GF, Tsai SY, Tsai MJ, O'Malley BW: Ligand-dependent conformational changes in the progesterone receptor are necessary for events that follow DNA binding. Proc Natl Acad Sci 1992, 89:11750-11754.

43. Leonhardt SA, Boonyaratanakornkit V, Edwards DP: Progesterone receptor transcription and non-transcription signaling mechanisms. Steroids 2003 68:761-770.

44. Rohe HJ, Ahmed IS, Twist KE, Craven RJ: PGRMC1 (progesterone receptor membrane component 1): a targetable protein with multiple functions in steroid signaling, P450 activation and drug binding. Pharmacol Ther 2009, 121:14-19.

45. Stevens SL, Ciesielski TM, Marsh BJ, Yang T, Homen DS, Boule JL, Lessov NS, Simon RP, Stenzel-Poore MP: Toll-like receptor 9: a new target of ischemic preconditioning in the brain. J Cereb Blood Flow Metab 2008, 28:1040-1047.

46. Chen G, Shi JX, Qi M, Wang HX, Hang CH: Effects of progesterone on intestinal inflammatory response, mucosa structure alterations, and apoptosis following traumatic brain injury in male rats. J Surg Res 2008, 147:92-98.

47. Feng $D, X u$ W, Chen $G$, Hang $C$, Gao $H$, Yin H: Influence of glutamine on intestinal inflammatory response, mucosa structure alterations and apoptosis following traumatic brain injury in rats. J Int Med Res 2007, 35:644-656.

doi:10.1186/1742-2094-8-42

Cite this article as: Hua et al:: Genomic profile of Toll-like receptor pathways in traumatically brain-injured mice: effect of exogenous progesterone. Journal of Neuroinflammation 2011 8:42.

\section{Submit your next manuscript to BioMed Central and take full advantage of:}

- Convenient online submission

- Thorough peer review

- No space constraints or color figure charges

- Immediate publication on acceptance

- Inclusion in PubMed, CAS, Scopus and Google Scholar

- Research which is freely available for redistribution

Submit your manuscript at www.biomedcentral.com/submit
Biomed Central 